\title{
FORMAÇÃO COMPLEMENTAR DE PROFESSORES: ANÁLISE DE UM CURSO DE ATIVIDADES POR INVESTIGAÇÃO
}

\author{
Complementary teacher training: analysis of a course of research \\ activities
}

Egláia de Carvalho (eglaia@ hotmail.com)

\author{
Mariana Aparecida Bologna Soares de Andrade (mariana.bologna @ gmail.com) \\ Universidade Estadual de Londrina - PR
}

\begin{abstract}
Resumo: Este artigo contém a análise de um dia do curso de formação complementar "Atividades Práticas de Genética, Evolução e Biotecnologia", desenvolvido com professores de Ciências Biológicas em formação inicial e continuada, ofertado para o Núcleo Regional de Educação de Cornélio Procópio - PR, com duração de oito horas. O propósito deste trabalho foi analisar a visão dos envolvidos ao participarem da elaboração de atividades práticas, sob o enfoque do ensino por investigação. O trabalho de caráter qualitativo teve como participantes um grupo de onze professores, dos quais sete eram de formação continuada e quatro de formação inicial. A análise dos encontros deu-se por meio de categorização. Os resultados obtidos evidenciaram que cursos como este proporcionam espaços para reflexão e discussão da prática docente, troca de saberes experienciais entre professores de formação inicial e formação continuada, e que apesar das dificuldades encontradas na elaboração das atividades estas proporcionaram transposição didática de conteúdo, e proporcionaram aos participantes compreender que é possível desenvolver atividades práticas com recursos já existentes.
\end{abstract}

Palavras-chave: Atividades Práticas; Resolução de Problemas; Genética; Docência.

Abstract: This paper contains the analysis of a day of the complementary training course "Practical Activities of Genetics, Evolution and Biotechnology", developed with teachers of Biological Sciences in initial and continuing education, offered to the Regional Education Nucleus of Cornelio Procopio - PR, lasting eight hours. The purpose of this work was to analyze the views of those involved when participating in the elaboration of practical activities, under the focus of teaching by investigation. The qualitative work was attended by a group of eleven teachers, seven of which were from continuing education and four from initial education. The analysis of the meetings took place through categorization. The obtained results evidenced that such courses provide spaces for reflection and discussion of teaching practice, exchange of experiential knowledge between teachers from initial and continuing education, and that, despite the difficulties encountered in the elaboration of activities, these provided didactic transposition of content, and provided participants to understand that it is possible to develop practical activities with existing resources.

Keywords: Practical Activities; Problem Solving; Genetics; Teaching. 


\section{INTRODUÇÃO}

Este trabalho resulta de um curso de Formação Complementar (com professores em formação inicial e outros em formação continuada), da rede pública de ensino do Núcleo de Cornélio Procópio - PR, promovido pela Universidade Estadual de Londrina - PR no intuito de concentrar experiências e inovações, para levar para as aulas de Ciências, ministradas no Ensino Fundamental, a investigação baseada em problemas como proposta de atividade prática.

De acordo com Krasilchick (2009), as atividades práticas visam criar um espaço em que é possível proporcionar ao aluno maior interesse no assunto a ser compreendido, envolvendo-o em uma investigação de caráter científico e na resolução de problemas.

Munford e Caixeta de Castro e Lima (2009) consideram formidável saber o real motivo da importância de se ensinar Ciências por meio da investigação, isso porque a Ciência ensinada nas escolas é totalmente diferente da que é praticada nas universidades, laboratórios e outros centros de pesquisa. Essa situação promove o aparecimento de duas Ciências distintas. Nas escolas, os alunos resolvem problemas já definidos e acabam por construir significados fixos e imutáveis. Já os cientistas analisam os problemas de uma forma menos pré-determinada e, consequentemente, geram significados menos definidos, que podem ser modificados.

Para Demo (1997, p.10), a pesquisa deve ser vista como um "instrumento metodológico para construir o conhecimento", e como um "movimento para a teorização e para a inovação". Para que a pesquisa possa ser realizada, é necessário um processo propício, em que exista ligação entre vários fatores, tais como: ótimo diálogo crítico dentro da sala de aula, acompanhado de exercícios que envolvam leitura, escrita e argumentação. Segundo Galiazzi (2001, p. 251),

[...] um trabalho de pesquisa pode ser resumido como um processo multicíclico, com três componentes: o questionamento, a construção de argumentos e a validação dos resultados, todos eles mediados pelo diálogo crítico dentro do grupo.

Moreira e Ostermann (1993) destacaram em seu trabalho a importância de ensinar que a investigação científica não começa na observação, caracteriza-se como um 
procedimento lógico, algorítmico e rígido, pois os cientistas sempre passam por várias etapas, erros e tentativas até chegarem a um determinado resultado; o conhecimento científico não é cumulativo e linear, mas, sim, um processo de construtivismo e que o conhecimento científico jamais pode ser considerado como definitivo.

O ensino por investigação baseado em problema demanda a compreensão do problema, fundamentá-lo, buscar, analisar e discutir dados para sua resolução; por último, são elaboradas hipóteses de solução, que devem ser colocadas em prática, para serem comprovadas (BERBEL, 1995).

A resolução de problemas de natureza investigativa, a partir de atividades práticas, pode permitir a associação entre o conhecimento trazido pelos alunos e o conhecimento científico. Segundo Pozo (1998) nossas perguntas ou inquietações sobre o mecanismo da natureza ou da tecnologia costumam aparecer sob a forma de problemas, inclusive fora da escola.

Esta metodologia "ocupa, sem dúvida, um lugar central no processo de ensinoaprendizagem", pois responde "aos pressupostos teóricos de maior peso na configuração atual da didática das ciências" (PERALES, 2000, p. 17).

A definição clássica, segundo Lester (1983 apud POZO, 1998, p. 15) de problema é a de "uma situação que um indivíduo ou um grupo quer ou precisa resolver e para a qual dispõe de um caminho rápido e direto que o leve a solução”.

Diferentes modalidades de resolução de problemas vêm sendo desenvolvidas e pesquisadas, possibilitando uma renovação na didática das ciências. As modalidades de resolução dos problemas podem ser divididas em três categorias, segundo Perales (2000, p. 21): “o tipo de solução (aberta ou fechada), procedimento seguido (exercícios, algorítmicos, heurísticos, criativos) e tarefa requerida (qualitativos, quantitativos, experimentais)."

Pozo (1998, p.15) elucida a diferença entre problemas e exercícios:

[...] Problema: uma situação que um indivíduo ou um grupo quer ou precisa resolver e para a qual não dispõe de um caminho rápido e direto que o leve à solução.

[...] Exercícios: Se baseia no uso de habilidades ou técnicas aprendidas (transformadas em rotinas automatizadas como consequência de uma prática 
contínua), limitando-se a exercer uma técnica quando enfrentamos situações ou tarefas já conhecidas, que não representam nada de novo, que podem ser resolvidas pelos caminhos ou meios habituais.

Para a elaboração de uma atividade de cunho investigativo, primeiro deve-se traçar a estratégia para alcançar a resposta, e, após isso, uma análise para verificar se o objetivo foi alcançado. Para tanto, Pozo (1998) estabeleceu alguns passos para a elaboração de atividades que envolvam problemas, e para que estes não se transformem em meras tarefas de exercícios escolares.

Os trabalhos escolares devem desenvolver atividades que possuam um paralelismo com o método científico, uma vez que na escola não existe a possibilidade do desenvolvimento de pesquisa como a realizada por cientistas. O que se propõe é um paralelo entre o método científico e as atividades de resolução de problemas, pois tanto na pesquisa científica como na aprendizagem de Ciências, o processo de mudança de representações de conceitos ocorre. Entretanto, um dos fatores que diferencia essa mudança está no fato de que os conhecimentos prévios (os conceitos) dos alunos provêm de diversas fontes e experiências do cotidiano. Transformar os conhecimentos vivenciados pelos alunos em conhecimentos elaborados conforme uma área da ciência é o desafio do professor para a organização dos conteúdos e atividades didáticas.

As estratégias de resolução de problemas possibilitam o desenvolvimento de atividades em pequenos grupos de alunos especialmente para "a resolução de problemas de maior complexidade" (PERALES, 2000, p. 75).

Durante a realização de uma atividade de cunho investigativo, o importante é o processo, mais do que o resultado, pois agregam temas geradores e tornam as aulas mais interessantes ao envolver o aluno em uma atividade intelectual que instiga sua curiosidade. Por isso, é importante observar que, para a elaboração de tais atividades, é necessário que o professor tenha uma boa formação. A participação de docentes em grupos reflexivos, como o deste curso, do qual se constituiu esta pesquisa, contribui para este tipo de formação.

Para atender às exigências e desafios da sociedade atual, os professores devem relacionar os conteúdos escolares com o cotidiano e com a realidade de seus alunos, para tornar o ensino significativo, possibilitando a transformação do indivíduo. 
A formação docente é um processo contínuo, desde a formação inicial até a formação continuada que se estende durante os anos de profissão. Garcia (1999) apresenta uma definição feita por Feiman (1986), que distingue quatro fases do aprender a ensinar, relacionadas à formação de professores. São elas: fase pré-treino, fase de formação inicial, fase de iniciação e fase de formação permanente. Estas fases referem-se ao percurso do professor ao longo da sua vida, e envolve passar pela insegurança inicial e desenvolvimento da segurança e confiança até o momento em que o professor começa a sair da situação de engessado e consegue adaptar as aulas ao seu estilo profissional, pois possui segurança e confiança suficiente para tanto.

Tal fato pode ser favorecido por meio da participação dos professores em grupos reflexivos sobre prática docente que permita inovar sempre o seu modo de ensinar de acordo com sua realidade escolar.

Nesta pesquisa, vamos analisar um espaço de formação de professores, apresentando abordagens de ensino, complementando a formação inicial, e proporcionando inovações para os participantes de formação continuada. O objetivo é compreender a visão que os envolvidos apresentam em relação às atividades de cunho investigativo para o Ensino de Ciências e as potencialidades e limites que os sujeitos sugerem para essas práticas.

\section{PROCEDIMENTOS METODOLÓGICOS}

Visando enfatizar a obtenção de dados descritivos, optamos pela pesquisa qualitativa, na qual os dados são obtidos no contato direto do pesquisador com a situação estudada, enfatizando mais o processo do que o produto e se preocupa em relatar a perspectiva dos participantes (BOGDAN; BIKLEN, 1994).

Participaram da pesquisa 11 sujeitos, sendo 4 estudantes de um curso de Licenciatura em Ciências Biológicas de uma Universidade Pública do Estado do Paraná (denominados por P1, P2, P3 e P4), e 7 professores da rede pública do Estado do Paraná (P5, P6, P7, P8, P9, P10 e P11), e os professores palestrantes do curso (E1, E2 e E3).

Como se optou por investigação qualitativa para o desenvolvimento deste trabalho, para entender de modo mais abrangente as concepções pessoais de cada participante, 
utilizamos a análise das transcrições das gravações audiovisuais, feitas no decorrer do curso, análise de material produzido durante as atividades de investigação e questionários.

Em função dos objetivos da pesquisa, durante as discussões no Grupo de Pesquisa em Ensino e Epistemologia da Ciência (GPEEC), iniciamos uma busca em revistas, em eventos e trabalhos relacionados à temática "Atividades Práticas de Genética, Evolução e Biotecnologia”. Também foi feito contato com o Núcleo Regional de Ensino da região e, como resultado, ficou evidente a escassez de material didático com essa temática, além da falta de cursos de formação na área que pudessem oferecer um suporte para o trabalho docente com atividades práticas de genética na região.

Neste âmbito, idealizamos proporcionar a estes professores um curso de atividades práticas relacionadas à "Genética, Evolução e Biotecnologia". As atividades realizadas em três dias de curso são adaptações de atividades das aulas de genética e evolução para o curso de graduação. Tais atividades foram adaptadas para adequar o conteúdo para o Ensino Médio. O material utilizado na Universidade consistiu-se em um livro que está em processo de publicação e, assim, ainda não pode ser referenciado.

Para este presente trabalho, serão analisados os dados coletados no primeiro dia de curso. Esta escolha ocorreu porque nesse dia houve enfoque nos aspectos metodológicos para a construção de atividades investigativas, enquanto que nos outros dois dias houve um enfoque nos conteúdos de genética, evolução e biotecnologia.

\section{DESCRIÇÃO DE ATIVIDADES}

O curso foi composto por três encontros de oito horas cada, aos sábados. Cada dia de curso contava com uma palestra inicial que discutia aspectos teóricos que seriam abordados na segunda parte do curso. Cada palestra tinha a duração de duas horas e as seis horas restantes foram destinadas para atividades práticas em grupo para os participantes.

Um professor em sala de aula não é alguém que apenas ministra aulas referentes ao conteúdo "x" ou "y". Os alunos são seres humanos complexos, com pensamentos, emoções, esperanças, expectativas, sonhos e uma infinidade de características individuais que não podem ser desconsideradas. A parte cognitiva é apenas uma dentre tantas outras. 
Por isso, a formação docente não termina quando o diploma da graduação está nas mãos do professor. É necessário que o docente sempre leia e faça cursos relacionados à formação completa do aluno, de modo a ajudá-lo a se tornar autônomo, crítico, participativo, ativo e transformador da sociedade em que vive. Pensando em contribuir para com essa concepção, o curso de formação complementar intitulado "Atividades Práticas de Genética, Evolução e Biotecnologia" teve três encontros de oito horas, aos sábados, levando em consideração que os cursos devem ser em horários que não entrem em conflito com as atividades da escola.

O primeiro dia começou com a apresentação do cronograma do curso, dos palestrantes e dos participantes. Em seguida, iniciou-se a palestra intitulada "Atividades práticas no Ensino de Ciências", proferida por E1. Depois disso, os sujeitos responderam um questionário inicial, elaboraram problemas de caráter investigativo, em duplas, abordando os temas de Genética, Evolução e Biotecnologia, para posterior análise e discussão sobre os mesmos.

Encerrada a etapa de criação dos problemas, os mesmos foram distribuídos aleatoriamente entre as equipes, evitando que elas recebessem os seus próprios, para que fossem analisados e discutidos.

Após a análise e apresentação de considerações pelos grupos, os problemas foram devolvidos para os participantes que os elaboraram para uma correção final. Todos os sujeitos contribuíram construtivamente em todos os momentos e comentaram a importância dos momentos de reflexão que puderam ter, como também, de compartilhar experiências.

A atividade visou a promover uma experiência de professor mediador, a lançar e a emergir nos grupos uma situação problema e, a partir dos equívocos que surgissem na produção dos problemas, que estes não fossem vistos como erros, mas como oportunidades de receber críticas construtivas e ajudar o grupo como um todo a melhorar as atividades criadas, para a identificação de possíveis obstáculos que os alunos poderiam enfrentar para solucionar. 


\section{RESULTADOS E DISCUSSÃO}

Conforme mencionado anteriormente, no primeiro dia, os participantes responderam um questionário previamente validado pelos pares do grupo GPEEC. Este continha uma parte com questões fechadas, para caracterização do participante e outra com questões abertas, relacionadas às concepções e uso de atividades práticas na escola e na sua formação.

Neste questionário inicial, nove dos participantes disseram que suas escolas possuem laboratórios, em que podem ser desenvolvidas aulas práticas. Os participantes já atuantes disseram possuir em suas escolas os materiais como televisores, computadores, internet, projetor, DVD, aparelhos de som, fotocopiadoras. Mas quando questionados sobre as dificuldades em realizar atividades práticas, contraditoriamente ao que tinha sido respondido na questão anterior, justificaram não preparar atividades por não possuírem materiais para realizá-las. Nota-se que os professores não associaram os materiais existentes nas escolas como possíveis meios para o desenvolvimento de atividades práticas.

Mesmo defendendo a ideia de que atividades práticas não necessariamente precisam de laboratório, e apesar das escolas em que estes professores atuam possuírem este espaço, em suas respostas fica evidente que este não é um espaço muitas vezes utilizado como ferramenta para aprendizagem.

As análises dos dados nos permitiram elaborar algumas questões: Como ajudar os professores a utilizar os materiais disponíveis? Como unir as atividades práticas que mais atraem a atenção dos alunos com os conteúdos a serem trabalhados? Como elaborar discussões e cursos que permitam aos professores construírem concepções sobre atividades práticas, bem como aplicá-las no cotidiano escolar?

As respostas dessas questões podem ajudar a nortear a instrumentalização das atividades práticas, ou mesmo a divulgação de trabalhos que vêm surtindo resultados positivos na forma de contribuir como multiplicadores de casos de sucesso. 


\subsection{ATIVIDADE PRÁTICA: ENSINO POR INVESTIGAÇÃO EM CIÊNCIAS}

Antes de solicitar a criação da atividade prática a palestrante E1 usou exemplos de estrutura conceitual de um problema pré-existente. Na análise deste problema, E1 abordou as etapas utilizadas para a criação deste modelo de atividade, de forma clara, para evitar "pegadinhas" que poderiam levar o aluno a se confundir quanto ao objetivo da proposta. Foi sugerido, também, o uso de diferentes fontes de pesquisa para a resolução de problemas em sala de aula. Durante as discussões sobre a atividade pronta trazida por E1, foi enfatizada a distinção entre "exercícios" e "resolução de problemas", e discutidas as diferenças entre problemas cotidianos, problemas científicos e problemas escolares. Nessa parte, o objetivo era apresentar uma metodologia de ensino que priorizasse a não passividade dos estudantes em sala de aula.

Após as explicações sobre a atividade, os participantes se organizaram em pequenos grupos para solucionar esse primeiro problema pronto, para entender o processo. Para a solução, foram explicadas aos participantes as estratégias da resolução, como levantamento de hipóteses, discussão, plano de estudo, e foi disponibilizado material para consulta.

Depois da solução do problema, a segunda parte da palestra caracterizou-se por explicar aos sujeitos estratégias para elaboração de atividades de cunho investigativo com o problema apresentado. Para início da atividade prática, os envolvidos receberam a proposta de criar, em duplas, atividades investigativas cuja característica é abordar temas de evolução, genética ou biotecnologia em forma de problemas. Para as atividades, os professores seguiram as orientações recebidas durante a manhã. Assim, foi explicado para eles que os problemas não poderiam ser exercícios, pois deveriam ter um enunciado claro e objetivo, que envolvesse o aluno em uma situação que o induzisse a uma pesquisa.

Os participantes, inicialmente, mostraram-se bastante inseguros em relação à atividade proposta e, por vezes, mencionaram o quanto a atividade fugia de sua rotina docente.

Vale ressaltar que esta insegurança inicial já era esperada pela palestrante. Neste novo cenário, as equipes deveriam criar uma situação que envolvesse seus alunos na atividade e, sempre que possível, deveriam discutir e identificar os obstáculos que podem ser encontrados pelos alunos, em sala de aula, com o objetivo de minimizá-los quando a 
atividade a eles for proposta. A intenção é a de que os alunos possam resolver a atividade de investigação, sem se sentir aquém da mesma, desistir ou optar por não participar.

Durante a realização da atividade, observamos os sujeitos um pouco ansiosos, inseguros em apresentar qualquer tipo de falha quando estavam com seus pares, pouco questionando, ou mesmo diminuindo sua participação com intuito de pouco se expor, não usufruindo do espaço disponibilizado para aprendizado e reflexão.

Depois de decorrido o tempo adequado para que todas as duplas terminassem a criação de seus problemas, foram produzidos cinco problemas. Apresentaremos, a seguir, a análise de somente três dessas produções, respeitando-se a escrita dos sujeitos.

\section{Sujeitos P1 e P2:}

Em uma fazenda no sul, onde há plantas que garantem a energia de animais herbívoros foi atacada por predadores carnívoros e insetívoros. Notou-se que em determinada época do ano houve um aumento de aves de rapina, o que acarretou na diminuição dos predadores terrestres. Com a falta de alimento as aves morreram e entraram em decomposição por organismos. Após um longo período, o solo ficou fértil novamente possibilitando a plantação.

Em uma relação ecológica, classifique sucessivamente os indivíduos a seguir em:

Produtor, consumidor primário, consumidor secundário, consumidor terciário $e$ decompositores.

Cobra - sapo - grilo - grama - bactérias - alface - gavião - preá.

O que são organismos autótrofos e heterótrofos? Monte a cadeia ecológica com os dados da questão anterior.

\section{Sujeitos P5 e P7:}

Durante a segunda guerra mundial as duas bombas nucleares que atingiram as regiões de Hiroshima e Nagasaki num cenário de destruição houve um jovem que perdeu a totalidade de pelos do corpo. E todos os seus descendentes nasceram sem pelos. Num país muito distante, descobriram-se que as famílias e seus descendentes apresentavam, como característica dominante, pelos excessivos e longos como os macacos. A maioria da população possui corpo revestido por pelos curtos.

Quais seriam as causas que levariam a essas características?

Baseado em seus conhecimentos sobre a camada de ozônio quais desses indivíduos teria melhor condições de adaptar-se a um ambiente que apresenta menor concentração de ozônio.

Sujeitos P9, P10 e P8: 
Júlia e Amadeu estudam no Ensino Médio e adoram o professor de Biologia que acabou de voltar de sua licença médica, pois teve hemorragia e precisou de transfusão de sangue. Procedimento sempre necessário quando ele se machuca. Para próxima aula o professor pediu para trazerem alimentos coloridos. Júlia pediu para Amadeu trazer pimentões coloridos. Na aula seguinte, Júlia ficou surpresa com a compra de Amadeu, pois o mesmo havia trazido pimentões de apenas uma cor. Quando questionado a respeito, Amadeu jurou que tinha pego um de cada cor. Julia ficou pensativa "Será que Amadeu está mentindo ou ele não enxerga cores?"

1. Analisando esta situação, como você explicaria o que ocorreu com o Amadeu que não distinguiu as cores dos pimentões?

2. O professor citado nesta situação apresenta alguma anomalia?

3. $\quad$ O que há de semelhante entre a anomalia do professor e seu aluno?

4. $\quad$ Por que estes tipos de anomalia aparecem mais no sexo masculino?

Com o intuito de analisar possíveis obstáculos que os alunos enfrentariam ao realizar as atividades elaboradas pelos participantes, os problemas foram distribuídos ao acaso para as outras duplas, pois a análise junto aos seus pares poderia enriquecer os problemas, principalmente por se tratar de um primeiro contato com este tipo de atividade. Ao final da análise dos problemas, as duplas deveriam dar um parecer o problema. Esta fase foi recebida com bastante entusiasmo pelos participantes.

Após a leitura, em voz alta, da atividade realizada pela dupla que elaborou o problema, os participantes que realizaram a análise deveriam dizer a resposta a que chegaram, se conseguiram realizar a atividade sem dificuldades e, se encontraram dificuldades, quais seriam. A análise dos problemas em conjunto nessa fase foi enriquecedora, pois todos participaram na construção de melhorias, com críticas construtivas. Sair da atividade de rotina de aplicar exercícios é um processo moroso, e exige grande esforço dos participantes. Um aspecto relevante apontado por Pozo (1998) é que qualquer pessoa que tenha contato com a atividade de resolução de problemas em um primeiro momento poderá encontrar dificuldades para encontrar a solução e deverá abrir mão de uma ampla série de habilidades para resolver a situação proposta. No entanto ao participar das reflexões e partilhar suas experiências, os participantes estavam uma atividade intelectual de compreensão de como aprimorar o processo de construção de uma atividade envolvendo a resolução de problemas.

O ensino por investigação considera o processo e não somente a resposta. Envolver o aluno em uma situação de atividade intelectual é relevante. Como sugestão para adequação da atividade elaborada por P1 e P2, conforme os passos indicados por Pozo 
(1998), P6 e P11 indicaram ser necessário "restringir um pouco mais as informações, de forma mais clara, inserir informações que pudessem ajudar a direcionar o objetivo a ser alcançado".

P11: a gente fica meio assim, com o pé meio atrás, pensando em dar as informações para não deixar tudo muito claro já, mas nesse ponto de vista a gente vai problematizar um conteúdo que vai ainda atrás. Então, a gente tem que passar mais informações, nós montamos o problema no nosso conhecimento. Tem que tomar, então, esse cuidado que eles não têm. $O$ conhecimento que nós temos, a leitura.

Ao realizar essa reflexão, a participante P11 demonstra o quanto é importante a contribuição dos pares nesse processo de construção de problemas investigativos, pois a dupla, ao realizar a atividade, concluiu que estava bastante claro o objetivo, mas ao receber as contribuições dos outros participantes, passaram a se colocar no lugar do aluno.

E1: Lembra uma coisa que falei no começo, uma coisa é você fazer uma atividade no sentido de avaliação, um assunto que já estudou, já sabe o conteúdo, ele lê o problema e vai responder, outra coisa é você oferecer atividade de caráter investigativo que para o aluno precisa ser um ponto de partida, e o ponto de partida tem que ser organizado, porque senão ele se perde, gera muitas dúvidas...

Dando sequência às atividades, a dupla P1 e P2 fez a leitura de seu problema, que é o primeiro problema apresentado acima, em voz alta, que foi analisado por P6 e P11:

P11: Nós que analisamos o texto, até assim nós consideramos o enunciado, a historinha boa, está bem explicada, só que nós achamos que as questões são de fixação de conteúdo.

P6: E deu uma atividade.

P11: É uma atividade... igual seria aquele exemplo que você passou, um enunciado levando em consideração... foi muito bom, deu para entender, só que vocês pecaram na fixação do conteúdo, passou um exercício, acho assim que para uma problematização ${ }^{1}$ teve falha no pôr uma situação, já tem exercício para resolver, não sei a gente chegou nessa conclusão.

P9: Eu penso que o enunciado, que nós estamos tão bitolados em faça isso faça aquilo que escreva isso, defina aquilo, que você já pediu na historinha... E1: Sim, mas eu acho que a história é boa, e aí depois da forma que eles fizeram a pergunta vocês desperdiçaram a historinha.

P6: Porque sem a historinha eles conseguem responder.

E1: E aí, como será que a gente podia mudar essas perguntas?

P2: Eu acho que, principalmente, talvez ao invés de colocar as espécies, pedir para colocar as que eles achassem, qualquer um que eles achassem.

P1: Eles sugerissem.

P2: Que eles achassem correto em cada lugar...

E1: Porque daí eles teriam de prestar atenção na historinha.

1 Problematização: uma estratégia de ensino investigativa, abordada neste primeiro dia de curso. No entanto, os participantes, quando utilizam a palavra "problematização" em seu discurso, o fazem por inferir que esta palavra está sendo utilizada no sentido de senso comum, e não no sentido teórico. 
P2: Talvez colocar as duas perguntas no final da história, e pedir para eles colocarem.

E1: É isso já mudaria. Pois ele fez a historinha e daí nas perguntas eu pensei, ah não.

A análise que a dupla realizou foi condizente com a proposta lançada. A atividade analisada foi bem elaborada, envolvendo o leitor na situação problema e instigando a curiosidade, mas, ao final da descrição da situação, ao realizar as questões, distanciou-se da proposta, que deixa de representar um problema e passa a se caracterizar como um exercício; desta forma, os participantes P1 e P2 sugeriram estruturar as perguntas de forma condizente com o enunciado criado, para envolver o aluno em uma investigação, que este seja desafiado a recorrer a ferramentas que o auxiliem na resolução. As discussões com o grupo geraram modificações necessárias, para enquadrar o que foi feito ao que foi solicitado de acordo com a proposta.

P3: Aqui seria, mais para o final, então? Eu teria toda a parte teórica aí você joga um problema desse, daí ele vai raciocinar, só que com certeza vai ter dúvidas.

P11: Aí sim, se você já tem trabalhado esse conteúdo, mas não como introdução do conteúdo.

Continuando com a proposta da atividade do dia, observamos que os participantes P1 e P2, P3 e P4 não realizaram, com êxito, a atividade prática de ensino por investigação, pois fugiram totalmente da proposta. P1 e P2 desvincularam as perguntas realizadas na atividade com a situação problema desenvolvida e fugiram do tema estabelecido, realizando atividades com tema relacionado à ecologia, sendo que a proposta lançada deveria envolver evolução, genética e biotecnologia.

A dupla P5 e P7 mostrou-se muito empolgada para a realização da atividade, mas levaram muito tempo até entrarem em consenso sobre o tema que iriam abordar. Foi a última a terminar o problema, que foi analisado por P3 e P4:

P4: A gente analisou que os objetivos dela, que era, eu não sei, que era demonstrar que tipo tem herdabilidade genética e que a perda do pelo poderia... não ter o pelo poderia prejudicar ou não a incidência dos raios solares, devido a camada de ozônio, a gente percebeu. Só que no começo do problema fala que ele perdeu todo o pelo, e que os descendentes dele nasceram sem pelo, mas eu aprendi que a característica de fator externo, que ocorre no decorrer da vida, não passa [para os descendentes], aí eu não sei se estava certo. Daí, eu até coloquei ali e, também, ao invés de colocar assim, uma característica que foi adquirida ao decorrer da vida colocar um tipo de mutação que ocorreu e que obrigatoriamente passou.

P5: Na realidade nós falaríamos que é sobre mutação gênica, [...], mas daí a gente evitou de citar aquilo que a gente gostaria que o aluno soubesse... 
P3: Mas daí tem que ver dos dois lados, porque se for a questão da mutação, na hora que você fala que o meio externo está afetando o fenótipo ele perdeu os pelos, mas daí a gente fica naquela, mas não altera genótipo, aí depois ele vem com a ...

P5: Ficou sem sentido.

P3: É ficou... ou duplo sentido.

Ao realizar a atividade, a dupla P5 e P7 escolheu um assunto que desconhecia, ocasionando um conflito entre conhecimento sobre a teoria evolutiva, genética e o conhecimento de senso comum.

P5: Então, nós pecamos no medo da gente colocar e o aluno já descobrirem o que a gente queria que ele descobrisse ao longo do conhecimento, sobre as evoluções.

P7: Que quando fala da segunda guerra já lembra das bombas atômicas, né? P5: É então... e as mutações.

P7: E a irradiação também, que já.

C1: Eu queria dizer que eu estava ouvindo daí eu estava pensando. Aí eu imaginei que no princípio houvesse essa confusão que vocês citaram aí, daí esse é um problema bem difícil, assim, poderia confundir a cabeça dos alunos com essa questão do lamarckismo, mas na teoria fosse possivel, se essa mutação afetasse a linhagem somática e a linhagem germinativa desse indivíduo, ele teria o fenótipo alterado e essa característica seria transmitida a outras gerações. Só que eu acho que o aluno do Ensino Médio ele não teria o discernimento pra conseguir entender que isso é possível e que isso não é lamarckismo e que talvez teria mais que o lamarckismo,

P5: Principalmente porque na hora de trabalhar os conteúdos a gente trabalha Lamarck e Darwin e para depois para entrar nas consequências das mutações então poderia realmente as observações estão corretas.

E1: E outra coisa que seria um problema aí, é o fato disso não ser realidade.

P7: Mas é realidade...

E1: Mas passou?

P7: Passou para a geração inteira, não tem pelo.

E1: Não tem cabelo, não tem nada?

P7: Não... nem sobrancelha nem cílio nada, pelo nenhum.

Desta forma, a análise do problema realizada pelos participantes foi de que seria necessário melhorar a descrição da situação apresentada, pois o problema foi baseado em uma informação de senso comum. A criação da história para envolver e estimular a curiosidade do aluno foi bem elaborada, mas o aluno encontraria dificuldades em realizar a pesquisa para respondê-la, pois encontraria contradições na situação problema.

Seguindo as leituras dos problemas, o último a ser lido foi das participantes P8, P9 e P10, que foi analisado por P5 e P7.

Das atividades desenvolvidas nesse dia de curso, a proposta desta equipe foi a atividade que se adequou melhor ao modelo de ensino por investigação. A história era 
envolvente, clara e objetiva, os alunos não somente precisariam pesquisar para encontrar uma resposta como desenvolver uma justificativa para a situação que ocorreu.

Envolver os professores em um processo de elaboração destas atividades de resolução dos problemas, compreendendo as etapas, como envolver o aluno na atividade intelectual, fomentar a sua prática docente, promovendo o domínio de procedimentos se apresentou um desafio de metacognição. Nesse sentido o "desafio do processo educativo, em termos propedêuticos e instrumentais, é construir condições do aprender a aprender e do saber pensar" (DEMO, 1996, p.30)

$\mathrm{Na}$ descrição do primeiro dia de atividade pode-se observar que a construção de saberes da profissão docente se inter-relacionam no trabalho, pois a profissão docente se estabelece com a atuação e desenvolvimento do professor em sua identidade profissional, e mesmo com as dificuldades apresentadas, a proposta de análise dos problemas em conjunto mostrou-se como um aspecto positivo. A insegurança inicial em discutir os problemas "dos outros" justifica-se pela não motivação de escolas e cursos de formação em disponibilizar momentos de trabalhos coletivos.

\section{ENTREVISTA AO FINAL DO PRIMEIRO DIA DE CURSO}

Após o término das atividades, E1 iniciou um processo de reflexão com os participantes sobre o que foi desenvolvido nesse primeiro dia de curso. As discussões, nesse momento, foram organizadas em duas categorias. Tais categorias mostram as reflexões que os professores tiveram em relação à construção coletiva de atividades pedagógicas e os aspectos pedagógicos envolvidos nesse processo.

Categoria 01: trabalho coletivo. Nessa categoria foram elencadas as reflexões dos professores sobre o processo de trabalho em grupo. Nesse aspecto, os sujeitos apresentaram a novidade em relação à proposta do curso:

E1: E então eu queria que vocês me dissessem o que vocês acharam de fazer essa atividade.

P6: Não é aquela coisa que nós imaginávamos... não sei se é todo mundo que partilha da mesma opinião, de chegar aqui, daí pega o trabalho elaborado prontinho. Mas positivamente, nós estamos trabalhando juntos. A equipe também, nós estamos construindo juntos, gostoso isso. 
Essa diferença em relação a outros cursos, ou seja, a necessidade de elaborar a atividade fez com que os sujeitos fizessem considerações sobre trabalhar em grupo. $\mathrm{O}$ primeiro ponto ressaltado foi em relação ao "tempo":

E1: Se tivesse que fazer sozinho?

P11: Uns dois dias talvez, saísse alguma coisa.

P6: Seria mais difícil, assim em questão do processo, mas definir o tema nós ficamos assim, ela queria puxar para um lado e eu queria puxar para outro. [...], daí gente é fácil, elas não entraram em consenso de trabalho, às vezes sozinha leva mais tempo, mas você não entra em contradição e tenha mais tempo para correr atrás, então você tem os dois lados da questão.

A fala de P6 foi complementada por P11:

P11: O bom de quando o outro dá opinião é que aponta as dificuldades que a gente tem e que não vê. Esse feedback que você dá também, isso é muito bom, que a gente vê onde errou e onde poderia melhorar também.

P6: Porque nós temos a nossa visão, mas o outro que vai ler e responder e não tem a mesma visão que você.

P9: Professora falando sobre o que eu achei, foi muito divertido porque a gente monta a história, coloca personagem. Mas eu acho que você dá vida a alguma coisa, e o aluno quando pega uma atividade dessas que nem nós [...].

A proposta da atividade também gerou reflexões de aspectos pedagógicos.

Categoria 2: Noções pedagógicas sobre os problemas. Duas falas foram consideradas significativas sobre a atividade. A primeira foi em relação ao professor como mediador da aprendizagem:

E1: Lembra que no início da minha apresentação eu falei que os professores falam muito que nos textos sobre professor mediador? Como vocês se entenderiam fazendo uma atividade como essa? Como entregariam o problema para os alunos? Como vocês descreveriam o que vocês iriam fazer em sala de aula?

P2: Primeiro a gente ia jogar a bomba lá para eles.

E1: E a partir dessa atividade, como vocês poderiam definir professor mediador, o que vocês poderiam dizer?

P11: É como nós fizemos, é isso, nós estamos no caminho certo, lê de novo o enunciado, assim que você quer, dando positivo, ou dá uma dica, se ler novamente vê que está fora e tem que ler de novo e tentar outro caminho, perceber que não está indo tem que direcionar.

Um segundo ponto salientado pelos sujeitos foi em relação a como essa atividade configura-se como uma mudança na postura do professor e na visão dos estudantes:

E1: É mais fácil ou mais difícil usar esse tipo de atividade?

P5: Não diria que é mais difícil, mas sim mais compensador, conhecimento com certeza.

P2: É mais difícil a elaboração.

P11: Por que do jeito que nós trabalhamos nós já pegamos o negócio pronto. P5: Não sei se na elaboração em si só, mas no conhecimento. Infelizmente não apresentam em sala de aula, eles são desinteressados, mas isso também não 
ajudaria eles a desenvolver um conhecimento? Por exemplo, lá, para dizer o que é mutação o que é seleção natural, defina, conceitue, e eles buscassem diferenciar o que é mutação e o que é seleção natural. É um conhecimento que eles nunca mais vão esquecer, então, também tem essas vantagens porque a gente também reclama muito de sala de aula, porque um presta atenção, um está num canto outro está lá no outro, e os outros querem andar, daí você entra na sala e você faz exatamente o quê? Só o que te mandam, e se talvez mudasse a forma da gente, nós que estamos tão acostumados a trabalhar, será que isso não teria vantagem no conhecimento deles? Eu acho que seria o caminho. A gente sempre escuta falar de professor mediador e daí pensa o que será que é, daí você cria uma situação problema e você entende tudo totalmente, como vai fazer o professor ser o mediador de conhecimento, não sei se eu estou certa.

E1: Está.

Em relação à atividade como uma proposta investigativa, ainda foi apresentada pelos professores uma opinião de que essa proposta só seria viável com estudantes que já tivessem tido contato com os conteúdos dos problemas:

P9: Se fosse um aluno de biologia no terceiro ano, ele terá condições. Se ele já tem uma noção muito boa de genética ele vai lá à parte de doenças e anomalias e ele vai conseguir aprender com muito maior facilidade, eu já trabalhei com os alunos.

Analisando as considerações realizadas pelos grupos foi possível perceber que desafiamos os participantes a enfrentar obstáculos de criar uma atividade investigativa, escolher o tema, imaginar cenários, se colocar no lugar do aluno. Estes professores conseguiram identificar as etapas que o aluno deve passar para encontrar uma solução para uma atividade de ensino por investigação. Essa reflexão sobre o papel do professor mediador proporciona o desenvolvimento da ação.

No que se refere ao se ensinar resolver problemas, Pozo acrescenta que não é suficiente "dotar os alunos de habilidades e estratégias eficazes" mas faz-se necessário “criar neles o hábito e a atitude de enfrentar a aprendizagem como um problema para o qual deve ser encontrada uma resposta "(POZO 1988, p. 14). Nesse caso, o aluno deve aprender a buscar meios e estratégias de encontrar respostas.

A posição docente nesta interação fica bem clara nos trechos em que os participantes mencionam que o professor espera sempre por uma resposta coletiva correta, sendo que a atividade prática de ensino por investigação não é uma atividade que possui uma única resposta correta. A intenção é que o aluno inicie uma atividade intelectual e que, com auxílio do professor, como mediador, faça suas próprias inferências 
e encontre uma solução cabível e lógica, transpondo conhecimentos e procurando ferramentas que possam auxiliá-lo nesse processo.

Mas os fatores determinantes para o sucesso desta atividade, visto que estes participantes não utilizam esta metodologia em sua rotina escolar, foram as reflexões e discussão sobre o trabalho coletivo.

\section{CONSIDERAÇÕES FINAIS}

Este trabalho se propôs a discutir e analisar, parcialmente, um curso de formação complementar envolvendo atividades sob o título "Práticas de Genética, Evolução e Biotecnologia”. São cabíveis, ainda, alguns apontamentos.

Apesar de o curso ter sido desenvolvido em um curto período, acreditamos que apresentou possibilidades positivas diante da realidade encontrada, uma vez que o professor em exercício dispõe de pouco tempo para dedicar à sua formação e, quando o faz, os cursos talvez não contemplem a elaboração de atividades. Compartilhamos do raciocínio de Garcia (1999) a respeito das fases de formação docente, as inseguranças apresentadas pelos participantes durante a realização do curso, podem ser compreendidas, pois alguns dos participantes que já se encontravam em fase de formação permanente (de segurança e confiança) foram inseridos em uma situação nova, de elaboração de atividades de resolução de problemas, e fora da sua zona de conforto, retornaram a fase de formação inicial com os demais participantes, apresentando assim certa insegurança, no entanto ao decorrer do curso, ao perceber o espaço como momento de reflexão e aprendizado, e não de avaliação, os mesmo conseguiram partilhar experiências e reflexões com seus pares.

De acordo com os dados coletados e analisados é possível indicar o sucesso do programa de formação complementar, visto que houve a transposição de conhecimentos entre as disciplinas, troca de saberes experienciais dos participantes, em fase de formação permanente com os participantes em formação inicial, contextualização dos temas dos dias de curso e também durante a realização das atividades práticas, além de discussões sobre a metodologia e aplicabilidade das atividades e de possíveis adaptações para a educação básica. 
As práticas apresentadas durante os dias de curso poderão contribuir para a construção de alternativas para realidade escolar destes docentes. Esses professores buscaram aprimorar o conhecimento sobre tópicos que julgavam inseguros em ensinar, ou insuficientes. Estes três dias de curso não proporcionaram somente espaço para expandir esses conhecimentos, mas serviram também como um espaço para trabalho em conjunto, principalmente para troca de saberes experienciais entre participantes em formação inicial e em formação continuada.

Consideramos trabalhos como esses importantes para o contexto atual. O professor necessita de cursos que o fomentem em sua rotina, pois este se mostrou inseguro e, por vezes, despreparado para ensinar conhecimento e avanços científicos na área que leciona, desconsiderando espaços como laboratório e equipamentos multimeios como recursos para atividades práticas. Ou, mesmo em posse da informação do modelo de aula que seus alunos preferem, não as realizam.

Observamos, também, que os professores se sentem ansiosos em realizar atividades práticas, expor pensamentos e dúvidas em relação à identidade docente com seus pares, seja pela cobrança social do papel do professor sempre realizar as atividades de forma impecável, característica evidente no grupo de participantes do presente trabalho.

No decorrer das atividades práticas, foram realizadas várias anotações sobre o desenvolvimento das mesmas, já que um dos objetivos do curso era adaptar as atividades práticas para a educação básica, observando-se a dificuldade que esses participantes encontraram em desenvolvê-las. Com as devidas adequações, incluindo tempo e materiais disponíveis em suas escolas, espera-se a aplicabilidade das mesmas com os alunos.

Com base nos dados coletados, podemos inferir que o objetivo principal dos participantes foi a busca dos saberes disciplinares e pedagógicos, visando ao desenvolvimento pessoal e melhor desempenho de suas atividades docentes, na busca de complementar a formação inicial, dialogar e integrar-se dos conhecimentos atuais.

Não somos ingênuos em afirmar que a formação docente, tanto inicial como continuada, ou complementar, que foi a situação analisada, garante a solução de todos os problemas educacionais. Porém, um profissional com baixa qualificação o é tampouco. 
Consideramos, por fim, que, ao promover um curso de formação complementar, os participantes passem da posição de meros espectadores para profissionais ativos, capazes de promover mudanças e melhorias em suas atividades docentes.

\section{REFERÊNCIAS}

BERBEL, N. A. N. Methodology of Problematizatlon: a methodological alternative suitable for Higher Education. Seminário: CI. Soc./Hum. Londrina, v. 16. n. 2., Ed. Especial, p. 9-19, out. 1995.

BOGDAN, R.; BIKLEN, S. Investigações Qualitativas em Educação. Uma introdução à teoria e aos métodos. Porto: Porto Editora. Coleção Ciências da Educação. 1994.

DEMO, P. Pesquisa e Construção de Conhecimento: metodologia científica no caminho de Habermas. Rio de Janeiro: Tempo Brasileiro, 1997.

FEIMAN, S.; FLODEN, R. The cultures of Reaching. In: M. Wittrock (Ed.) Handbook of Research on Teaching. 30.ed. New York: Macmilian, 1986, p. 505-526.

GALIAZZI, M. do C.; ROCHA J. M. de B.; SCHMITZ, L. C.; SOUZA M. L.; GIESTA, S.; GONÇALVES, F. P. Objetivos das atividades experimentais no ensino médio: a pesquisa coletiva como modo de formação de professores de ciências. Ciência \& Educação, v.7, n.2, p.249-263, 2001.

GARCIA, Carlos M. Formação de professores para uma mudança educativa. Porto: Porto Editora, 1999.

KRASILCHIK, M. Prática de ensino de biologia. 4. ed. São Paulo: Editora da USP, 2008.

MOREIRA, M. A.; OSTERMANN, F. Sobre o ensino do método científico. Cad.Cat.Ens.Fís., v.10, n.2: p.108-117, ago.1993.

MUNFORD, D., CAIXETA DE CASTRO E LIMA, M. E. Ensinar ciências por investigação: em quê estamos de acordo? Ensaio Pesquisa em Educação em Ciências [online]. Disponível em: < http://ipn.redalyc.org/articulo.oa?id=129516644007>. Acesso em: 18 out. 2016.

PERALES, F. J. de. Didática de las ciencias experimentales. Alcoy/Espanha:Marfil, 2000.

POZO, J. I. (Org.). A solução de problemas: aprender a resolver. Porto Alegre: ArtMed (1998).

POZO, J. I.; POSTIGO, Y. Los procedimientos como contenidos escolares: uso estratégico de la información. Porto Alegre: Artmed, 1998. 